\title{
Complex, high risk and indicated patients in Croatia: are we ready?
}

\author{
Irzal Hadžibegovićc*, \\ Mario Sičaja, \\ Ognjen Čančarević, \\ Ante Lisičić, \\ Boris Starčević
}

University Hospital Dubrava,

Zagreb, Croatia

RECEIVED:

January 31, 2018

ACCEPTED:

February 10, 2018

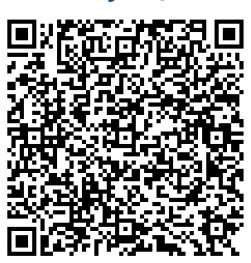

$\square$ Cardiologia Croatica 2018:13(1-2):40.
KEYWORDS: high risk patients, complex percutaneous coronary interventions, protected percutaneous coronary interventions.

CITATION: Cardiol Croat. 2018;13(1-2):40. | https://doi.org/10.15836/ccar2018.40

*ADDRESS FOR CORRESPONDENCE: Irzal Hadžibegović, Klinička bolnica Dubrava, Avenija Gojka Šuška 6, HR10000 Zagreb, Croatia. / Phone: +385-91-5333-091 / E-mail: irzalh@gmail.com

ORCID: Irzal Hadžibegović, https://orcid.org/0000-0002-3768-9134 • Mario Sičaja, https://orcid.org/0000-0003-0773-4720 Ognjen Čančarević, https://orcid.org/0000-0002-1285-8042 • Ante Lisičić, https://orcid.org/0000-0002-4365-9652 Boris Starčević, https://orcid.org/0000-0002-3090-2772

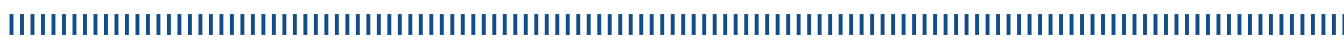

Complex, high risk and indicated patients (CHIP) for percutaneous coronary intervention have gained a lot of interest in the last several years, and revascularization strategies for complex multivessel and patients with chronic total occlusion (CTO) are being currently scrutinized beyond SYNTAX trial. ${ }^{1}$ It appears that in complex multivessel disease percutaneous coronary intervention (PCI), coronary artery bypass grafting or hybrid strategy selection does not matter if revascularization strategy is both indicated and total. CHIP group mostly comprises of patients selected for conservative treatment because of high risk after a heart team meeting, but it has been found that total revascularization of hemodynamically significant lesions improves survival in those patients. In fact, it seems that outside myocardial infarction, this subset of patients is the one where interventional cardiology treatment dramatically shows benefit in the terms of survival and quality of life. Interventional cardiology teams that plan to embark into CHIP have to be equipped, experienced, and educated in fractional flow reserve (FFR), intravascular ultrasound, CTO intervention techniques, plaque modification techniques, thrombus burden solutions and at last hemodynamic protection. However, results with the intra-aortic balloon pump or extracorporeal membrane oxygenation (ECMO) in CHIP subset did not prove beneficial. Currently, Impella 2.5 or Impella CP are temporary ventricular support devices preferred for protected PCI in hemodynamically stable high-risk patients, but it has not yet been used in our clinical setting.

We analyzed our center experience with complex high-risk patients indicated for revascularization from 2012 to 2017. We observed a notable increase in CTO and plaque modification procedures, without significant increase in complications. However, reimbursement issues disabled the growth in number of FFR and IVUS procedures in complex patients. Although hemodynamic protection with ECMO had a relatively good reimbursement policy, initial clinical experience did not show promising results in CHIP subset, as compared to acute setting.

In conclusion, Croatian interventional cardiology centers entering CHIP territory need integrated heart team education, adequate equipment and adequate reimbursement for complex high-risk patients, while appropriate hemodynamic support still remains an unresolved issue.

LITERATURE IIIIIIIIIIIIIIIIIIIIIIIIIIIIIIIIIIIIIIIIIIIIIIIIIIIIIIIIIIIIIIIIIIIIIIIIIIIIIIIIIIIIIIIIIIIIIIIIIIII

1. Becher T, Baumann S, Eder F, Perschka S, Loßnitzer D, Fastner C, et al. Comparison of peri and post-procedural complications in patients undergoing revascularisation of coronary artery multivessel disease by coronary artery bypass grafting or protected percutaneous coronary intervention with the Impella 2.5 device. Eur Heart J Acute Cardiovasc Care. 2017 Jun 1:2048872617717687. https://doi.org/10.1177/2048872617717687 